Pakistan Journal of Education

Vol.36, No.3, 2019, 19-38

\title{
Advancing Public Education in Pakistan through a Teacher Exchange Program in the United States
}

\author{
Madeline Milian* \\ Sajid Ali Yousafzai**
}

\begin{abstract}
This study examined a multi-year teacher exchange program that included Pakistani secondary English teachers and took place at a midsized institution of higher education in a western state in the United States. It aimed to understand the program's possible impact on advancing Pakistan's public education after the completion of the program. A major goal of the study was to analyze how participating secondary English educators in the program viewed, interpreted, and could transform the new knowledge and strategies learned in the program into effective practices in their Pakistani educational settings. The information for this study was gathered from open-ended questionnaires and multiple focus group discussions with 37 in-service secondary teachers who attended this 6-week professional development program. Participants concluded that low-class size, technological tools, student diversity, teacher-student interactions, social and cultural practices, and classroom structures were some of the major differences between the U.S. and Pakistan's classrooms. Information on educational and practice similarities that are found in both countries, as well as culturally acceptable adaptations are also included as part of the findings of the study. Recommendations for future work are suggested as a way to confirm how these exchange programs generate changes in teaching practices.
\end{abstract}

Keywords: teacher exchange programs; comparative education; English teaching; Pakistani education; professional development.

\footnotetext{
*Professor, University of Northern, Colorado,USA. Email: madeline.milian@unco.edu ${ }^{* *}$ Assistant Professor, National University of Modern Languages, Islamabad.

Email: sayousuf@numl.edu.pk
} 


\section{Authors' Note}

Teachers participating in the study received funding through a Teacher Exchange program sponsored by the U.S. Department of State that was funded by the U.S Government. This study was not funded by these agencies and the findings and opinions are only those of the authors.

\section{Introduction}

While some educators may only have the opportunity to improve their international perspectives by reading books, participating in social media, watching films, or taking academic coursework, others may be fortunate to travel abroad and participate in an international teacher exchange program (Bilash \& Kang, 2007; Heyl \& McCarthy, 2003; Rios, Montecinos, \& van Olphen, 2007). Becoming more mindful and more aware of other cultures, teaching strategies, specialized curriculum, diverse pedagogy, and observing how teachers in other countries plan and deliver instruction can potentially assist teachers in transforming their own professional practices back home (Heyl \& McCarthy, 2003; Smith, 2013)

Researchers who have studied the benefits obtained by preservice and in-service teachers who have completed teaching opportunities abroad have listed the positive professional and personal results of these experiences (Bilash \& Kang, 2007; Carriedo, De Nava, \& Martínez, 2017; Cook, 2009; Lee, 2011; Rhodes \& Milby, 2016; Shiveley \& Misco, 2015). Among the benefits found through study abroad and teacher exchange professional development programs, teachers have confirmed that these opportunities have provided advantages when searching for teaching positions, allowed them to gain cultural awareness and better global understandings, increased their confidence as people and professionals, improved their second language skills, created networking opportunities, and improved their ability to reflect on their teaching practices.

Since previous studies have stated the beneficial results of study abroad and teacher exchange programs, it is reasonable then to continue exploring the transformations educators experience as a result of their participation in such programs. It is also important to understand how educators who attend these programs perceive the educational practices they observe in the settings where these exchange programs take place. These perceptions can be informative to hosts institutions and school 
systems and can help them reflect on practices that are inherent to their settings. Ultimately, how the practices observed by participating teachers in exchange program actually lead to improvements in their teaching practices once they return home, should be a priority when designing and evaluating how these programs advance education across settings.

\section{Literature Review}

Educators working in countries where public education is characterized by lack of universal access and quality education for all students can improve both their advocacy and teaching skills by participating in international professional development programs in countries with higher standards and governmental commitment to public education. Pakistan, the country where the teachers in this study lived and taught, provides an example of an educational system where many students still lack access to public education particularly in rural areas, literacy rates are lower than desirable with stark disparities between male and female rates, there are limited opportunities for students with disabilities in public schools, teachers face challenges with resources and professional development, schools are not well maintained, hiring practices are politicized often leading to the hiring of unqualified teachers, and in general public education is not well supported by the government (Hussain, 2015; Khan, 2018; Rashid \& Mukhtar, 2012).

In terms of educational practices, teachers in Pakistan continue to use very traditional teaching methodologies that emphasizes the transmission paradigm of learning in which the students depend on the teachers to provide the information from the textbooks (Nasrin, 2013). As Khan (2018) indicated, the methodologies used by teachers in Pakistan are framed within a didactic approach to teaching and learning that concentrate on content, but fail to address the student's cultural, developmental, emotional, social, and physical well-being. In these traditional Pakistani classrooms, teachers select teaching strategies that favor their own teacher-centered style and they "transmit" textbook facts to students who are expected to memorize and reproduce the same in examinations and neglect active participation and engagement of students (Ahmed, 2013).

To alleviate educational challenges and improve teaching practices in Pakistani public schools, current efforts for professional development are taking place sponsored by national and international organizations with the aim to expose teachers to new methodologies and experiences that will consequently result in improved teaching practices 
in Pakistani classrooms. New methodologies learned by the participating teachers, will not only be practiced by those selected in professional development programs, but will also be shared by the participants in their local schools and regions; hence creating opportunities for other educators to learn and building capacity in the educational system. This study is based on one of the professional programs sponsored through the U.S. Department of State and two Non-governmental organizations (NGO).

Our work was guided by the necessity to improve the Pakistani educational system as well as to understand how Pakistani educators participating in a teacher exchange program view, interpret, and can apply the new practices they observe and learn into the reality of their educational settings back home. As educators confront new ways of practicing their craft, they constantly need to analyze how these new ways of approaching teaching and learning can be successfully implemented in their context given the financial and human resources as well as cultural expectations that exist in their communities. By intentionally generating opportunities to discuss differences, similarities, and appropriate ways to apply new ways to approaching teaching and learning, educators can begin envisioning their new role and use of new knowledge in a culturally appropriate manner and within the constrains that are common to developing countries. It was important to acknowledge the limitations and challenges inherent in the practice of 'transporting' educational methodologies to settings that are socially, economically, political, and religiously different without reflection and examination. We maintained that without examining and reflecting on how these new practices needed to be adapted, transformed, and ultimately practiced in the teachers' settings back home, significant learning opportunities would have been missed. Consequently, our ultimate goal was to engage the participants on reflective discussions of differences and similarities within the two distinct educational contexts; that is, classrooms in the United States and Pakistan, with the intention that they would begin developing ideas and plans that will help them apply the new knowledge and skills learned as part of the profession development program.

There has been a great deal of discussion concerning quality of teaching in Pakistan. For example, to illustrate the sentiment of the discussion, The National Education Policy explained that,

There is a consensus amongst all stakeholders that the quality of teachers in the public sector is unsatisfactory. Poor quality of teachers 
in the system in large numbers is owed to the mutations in governance, an obsolete pre-service training structure and a less than adequate inservice training regime.(The National Education Policy, 2009, p.42)

Educators and public education in Pakistan are often generally criticized because of issues related to quality. Once employed, teachers seldom obtain any opportunities to improve their content knowledge or enhance teaching skills. Recently there has been a trend for seeking PD trainings abroad. Such trainings or fellowships are fully funded, offered in a short term and supported by foreign governments. Many educators, motivated by the opportunity to improve their teaching skills and advanced their professional development, have applied and participated in these programs.

The low percentage of educational expenditure also contributes to the low quality of education in Pakistan. According to the analysis in the 2015-2016 budget, the total federal and provincial allocations for education are only about Rs.734 billion, that constitutes 2.68 percent of the GDP. This much allocation for education is derisorily low when compared to the four percent of GDP recommended by UNESCO for developing countries (Haider, 2014).

Quality of teaching is certainly linked with teachers' qualifications, training and professional development. The quality of teaching is inconsistent and low in public schools because of ineffective and almost exclusive theory-focused pre-service and in-service teacher preparation. Consequently, the participation of Pakistani teachers in professional development exchange programs is fundamental to the improvement of teacher preparation and teaching quality in Pakistan as most alumni are committed to conduct professional development activities in their communities which leads to multiplying effects in the overall quality of education and teacher preparation.

Pakistan's public educational system suffers from serious and multiple problems such as lack of proper planning, social constraints, gender gap, cost of education, war on terror, funds for education, and technical education (Hussain, 2015). Consequently, studies that aim at advancing the educational system can potentially alleviate the critical situation that exists for students and teachers in Pakistan.

This study analyzed the practices that participating teachers identified as similar to or different from their context in Pakistan, as well as practices that they considered beneficial to use in their setting or not appropriate to use in their educational context in their communities. It was assumed that not all practices observed were replicable and that 
teachers had to use their creativity and cultural knowledge to selectively apply the practices learned in the program in their classrooms, either in a modified manner or not at all. Also, of interest, were cultural classroom practices observed in the U.S. that teachers identified as not common or not present at all in their context. We classified our work as comparative in nature and understood that both educators in Pakistan and the U.S. could benefit from the findings. Our specific research questions included:

1. How do Pakistani secondary teachers participating in a professional development program in a western state in the United States perceive the differences and similarities between the schools in Pakistan and the schools they visited during their professional development?

2. What innovations, strategies, and policies may be more beneficial to replicate in Pakistani schools?

3. What innovations, strategies, and policies may be less beneficial to replicate in Pakistani schools?

\section{Research Methodology}

The research methodology for this study was guided by previous studies on comparative pedagogical practices and innovations (Alexander, 2000, 2001; Law 2007), and was inspired by concepts of cultural complexities that exist when comparing practices across cultures (Potts, 2007). We constructed an electronically written questionnaire that was distributed to participants accompanied with an explanation of the study, which was approved by the first author's Institutional Review Board, and the consent letter. Prior to sending the electronic questionnaire to the participants, the study was explained in details and participants were told to expect the questionnaire. The volunteer nature of the study was emphasized to make sure that participants understood that this study was not part of their professional development program and that they did not have an obligation to participate. Additionally, focus group interviews were conducted to obtain more supporting information, as well as to clarify some of the answers provided as part the written questionnaires.

\section{Research Instruments} included:

Data for this study were collected from two main sources which

Written Questionnaire: A six-item open-ended questionnaire was used to ask participants' views about the differences and similarities between school systems, most helpful and least beneficial practices observed in 
the U.S. school, strategies that could not be used back home, as well and beneficial strategies that should be implemented in their communities. Each participant completed the written questionnaire electronically and submitted it to the researchers.

Focus Group Discussion: A similar open-ended questionnaire was used for focus group discussions. To respect cultural norms, four genderspecific focus group panels were created. The purpose of the focus group discussion was to get additional insight and details from participants. The focus groups were instrumental in providing illustration and examples of the information that was gathered through the written questionnaires. It also helped clarify differences in opinions based on regional and/or socioeconomic differences.

Upon completion of the questionnaires, the researchers gathered the information from each questionnaire using a constant comparative method (Corbin \& Strauss, 2008). Once saturation was reached (Charmez, 2008) we used themes, both common and unique, to develop a focus group interview protocol. We asked participants to break into small gender-specific focus groups to discuss their questionnaire answers as well as to ask new follow-up questions that were developed from their answers. Participants' answers were audio recorded. During the focus groups the researchers listened to the participants' answers while also taking short hand-written notes.

Fraenkel and Wallen (2006) suggested that the use of a variety of instruments enhances the validity of the study. Gathering similar information through two different types of data collection sources, allowed us to increase the validity of the information participants shared with us.

\section{Participants}

Participants for this study were a convenience sample (Creswell, 2013; Patton, 2002) as they were participating in a funded professional development program at our campus from 2011-2016.Participants were in-service teachers in public schools in Pakistan. Thirty-seven participants completed the written questionnaire. Of those who completed the questionnaire $15(40 \%)$ were male and $22(60 \%)$ were female participants. Twenty-three participants contributed to the focus group discussion. Of those who contributed to the focus group discussion, 13 (56\%) were male and 10 (44\%) were female participants. Participants' age ranged from 26 to 42 years, had an average of six years 
of teaching experience, and came from the provinces of Baluchistan, Punjab, Sindh, and Khyber Pakhtunkhwa (KPK).

The participants conducted their classroom observations in a public-school district located in a western state. They were specifically placed in either a middle or high school classroom as they taught in secondary schools in Pakistan. Each participant spent 40 hours in the same classroom.

Teachers in this study engaged in identifying and analyzing educational practices and the cultural assumptions that are connected with these practices. Findings are not only significant for Pakistani teachers, principals, educators, and policy makers but also for other international educators when considering incorporating educational practices across settings. Discussions on how educational systems vary according to the need of the society and cultural norms in which they function provide opportunities for reflection. Indeed, factors such as school and community cultural particularities, human and financial resources, and the physical space where teaching and learning takes place are among the factors requiring consideration when determining best practices for teachers within a given educational context.

\section{Results and Interpretation}

As previously mentioned, participants were asked to identify educational practices that were similar and different in the two educational practices as well as identify practices that would be appropriate or not to replicate into their classrooms and schools in Pakistan. Following we will explain the differences, similarities, and considerations for replication. It is important to note that the participants' reflections are specific to the observations they conducted in the public schools' they were assigned to during their professional development program. While those schools were very typical of the schools found in the United States, these observations may not be generalized to private or religious schools. 


\section{Differences}

In terms of differences, the participants stated that the following characteristics were very noticeable: technology was more available and widely used by teachers, students and administration; students asked questions and engaged with teachers much more frequently than students in Pakistan; mixed gender classrooms in secondary school is the norm in the U.S., but not in Pakistan; there was more diversity in the classrooms they observed; the school day is much longer in the U.S. where meals are provided with in the premises; and the school setting is much more informal as reflected by clothing in contrast to uniforms in Pakistan, flexible sitting arrangements, and interaction styles.

The focus group discussions also listed other striking differences which included the standardized examination system of the U.S., which is used at the elementary level; as well, whereas in Pakistan, it is used only at grades 5th, 8th, 9th and 10th specifically. Students' individual need and disabilities are accommodated to in the classrooms much more affectively in the U.S. and the teachers are trained in educating special children along with the general education students, whereas these areas are neglected in Pakistani context. Students in the U. S. are provided with more services to support their education such as transportation, professional counseling, class libraries and well decorated classrooms whereas Pakistani schools lack those services. While commenting on the curriculum, the participants also mentioned the differences in curriculum including subject choices, grading system of students, teachers' evaluation and monitoring system. The teachers have a licensing procedure in the United States which keeps them abreast with the new practices and makes them more accountable while Pakistan does not have such licensures. The participants also commented on institutional practices which differ in both contexts. In Pakistan, the schools are more discipline oriented where religious and moral values are promoted, and teachers encourage civic services including election process, vaccination and social awareness programs while in US those practices were not observed.

Teachers' comments are included here to illustrate some of the identified categories:

\section{Diversity}

"One of the biggest differences between U.S. and Pakistani school was the diversity. There are international students in U.S. classrooms including students from Mexico, China, Guatemala, Ireland 
and many more countries. The situation in Pakistan is quite different. In Pakistan, there are four provinces, but you cannot find the students of one province in another province. I was very impressed by the efforts of U.S. teachers who were teaching the students of different caste, creed, and color."

\section{Resources and Classroom Environment}

"The schools I observed were equipped with resources, technology, space. Teachers are well trained, tolerant. Activities are student centered. There is more emphasis on students than on syllabus. Extra-curricular activities, community services are common. Students have more freedom of expression and choice as well. The classrooms are decorated, with all the facilities, books are so colorful and environment is conducive to learning."

\section{Classrooms and Teacher/Student Interactions}

"One of the main differences between the Pakistani and American schools is that of the number of students in a class. In an American class, the average number of students are 30 while in Pakistan, the average number of students are mostly 70.The second main difference is the teaching method of the American teachers who teach in a free and frank manner and hence the students enjoy it while in Pakistan, the classes are mostly tense because of the authoritative behavior of the teachers."

\section{Teachers' Working Spaces}

"The teachers I observed had allocated rooms. This helps them to make their rooms more resourceful according to their needs. Whereas in Pakistan it is the opposite as the teachers have to move to the classes. Classes are more spacious as the number of students is less and there is enough room for the students to engage in group activities. Classroom management techniques are different to some extent as the relationship between students and teachers is more of respect in Pakistan."

In general, there were multiple differences identified by the teachers which were the result of better funded public schools, educational policies that provide access to public education to all students; including those with disabilities, student-centered teaching practices, teacher licensure regulations which required a university degree and a state license to teach, a diverse student body that reflects the 
racial, economic, and religious composition of the community, standardized testing practices, the availability of extracurricular activities such as sports, music, and theatre, and educational support services to address students' social, emotional, and academic concerns.

\section{Similarities}

Participants stated few visible similarities. They mentioned that in both countries many teachers are devoted to their profession and demonstrate passion in their teaching. In both countries, teachers are concerned about their students' progress, standardized tests are used, teachers' salaries are low in comparison to other professions, and that the grade division are similar. The discrepancy in public and private school system exists in both countries where less affluent students attend public schools and often more privileged families prefer private schools. Multilingual students are found in both countries where many students study English as a second or third language. Illustrative comments of similarities included:

\section{Teachers' Commitment and Passion for Teaching}

"Teachers are dedicated and hardworking in both countries. Attention to co-curricular activities is given in both the countries. Parentteachers' meetings take place in both the set-ups."

"Teachers in each country keep a passion for their profession. In the U.S., teachers are making the best use of modern teaching tools whereas in Pakistan, teachers are making the best use of their oldfashioned teaching practices."

"The most dominant similarity is the passion and enthusiasm for teaching which I find is same in both countries. The teachers in both countries are passionate about their teaching and they love it from the core of their heart."

\section{Teaching English as a Second or Foreign Language}

"We have same kind of problems of teaching English with only the difference that here you teach ESL and we teach EFL."

"Many students are non-native speakers of English." 


\section{Teachers' Salaries}

"In both countries teachers are not satisfied with their salaries."

"Teachers are not well paid both in Pakistan and USA."

"Both the teachers in U.S. and Pakistan get less salary as compared to other professions."

Similarities listed by the participants were predominately based on the passion and commitment displayed in both countries by teachers, the unfortunate fact that teaching is a relatively low-paying profession as compared to other professions with similar education requirements, students learning English in the context of school, and the inquisitive nature of students.

\section{Most Beneficial Knowledge/Skills Learned and Practices Observed}

Teachers identified activity-based learning as extremely beneficial to them and expressed a desire to use it in their classrooms. They were hopeful that through the strategies they observed and learned including language development techniques, micro teaching techniques, addressing diversity, and different modes of evaluation, they would be able to develop activities that will increase student engagement. Teachers were also motivated to include more technology as part their teaching as an instructional tool, and not just as a record-keeping tool. Participants also noted that learning new positive behavior management techniques that facilitated group work and the use of more structured lesson plans formats will be very helpful to them. Some of the teachers' comments included:

\section{Activity-based Learning and Students' Centered Learning}

"Some of the activities that I observed at school as well as in my professor's class like A.B.C. Brainstorming, Rotating Trios, Hot Potatoes, Pre-Test with a Partner, etc. are going to be really helpful in Pakistan. Moreover, the strategies of getting students motivated when they lose interest and feel bored like 'Five in the air', 'Thumbs up and Thumbs down', short stretching exercises are also good to be done in Pakistani classes."

"I will implement most of the SIOP model strategies to promote collaborative learning." 
Use of Technology

"I now can think about using technology in the classrooms. While we do not have the technology in the classroom, we now know how to use the technology and the possibilities that if offers."

"I can find educational resources through technology and use it in the classroom. Some of the teachers will do monthly Skype meetings with the classrooms."

\section{Addressing Diversity}

"We have learned much about diversity and the importance of education for all children."

"The diversity we observed here has influenced us very much. In our country, we only want to teach our own group."

Certainly, teachers identified multiple areas that they found most helpful in their future practice back in Pakistan, most of the identified areas were directly connected to the work teachers conduct with their students in the classroom. While some of them recognized the limitations in implementing some of the new knowledge and skills due to lack of resources, they appreciated learning about the possibilities and developing a new vision for the future.

\section{Least Beneficial Knowledge/Skills Learned and Practices Observed}

Participants were asked to identify knowledge, skills, and practices that; while important in educational setting in the U.S., my not be easily transported or implemented in the Pakistani educational setting. Teacher identified areas that were connected with resources, such as learning to use a Promethean Board since they will most likely not have one in their classrooms, particularly in rural areas. They also mentioned the practice of using the school library to complete assignments as not replicable in their communities as many of them did not have libraries at their schools. Additionally, they identified learning about music classes and behavior interventions as not very beneficial as music classes are not offered at their schools, and student behavior problems rarely exist in their settings. This question was the one that identified the fewest areas.

\section{Practices not Applicable for the Pakistani Educational Context}

Cultural considerations when learning and applying new educational methodologies are inherent in all teacher exchange programs. We asked teachers to reflect on the cultural applications of the practices they had observed and on the new knowledge and skills they 
had learned. Teachers commented that the idea of having their "own" classrooms was not practical in their setting. While they admired how classrooms were decorated to support learning, they mentioned that in Pakistan secondary teachers rotate classrooms making it difficult, if not impossible, for individual teachers to decorate a given classroom. They mentioned that the longer school days and provision of lunch to students are also not appropriate according to Pakistan context as students engage in other activities including religious education at home. They added that in Pakistan, the frankness among boys and girls is not appreciated as it is culturally not acceptable; hence, such mixed-gender educational environments and interactions are not practical in public schools. They identified the use of cell phones on campus as also not allowed in Pakistani secondary schools; consequently, the activities based on mobile apps are also not possible to practice. Lastly, they identified the informal manner in which students and teachers dress to attend school as not being acceptable in Pakistan. Some of them mentioned how in Pakistan all students wear uniforms but that is not common in our public schools. Some illustrative comments included:

"The long school day will be inappropriate for teachers or students because of the weather conditions and the social settings."

"The informality in the classroom here would be considered inappropriate in Pakistan."

"Students' relationship with each other. Boy/girl relationships in high school."

In general, many of the areas identified by the teachers were related to social norms; which in the context of Pakistan, are influenced by religious practices.

\section{Practices Better Implemented in Pakistan}

One last question was included requesting the participants to identify educational practices, policies, or students and teachers' knowledge or skills that they believed were more advanced or better practiced in Pakistan.

When identifying practices that they believed were better implemented in secondary schools in Pakistan, participants mentioned that they believed that morning school assemblies, handwriting instruction, the use of uniforms, school discipline, shorter school timings, single gender classroom, teacher working hours and teacher incentives including different leaves with full pay were positive practices that they would like to continue to see in their communities at the secondary level. 
In reference to higher education, they mentioned the higher cost of higher education in the United States as compared to Pakistan. Some of the comments included:

"Use of uniforms in Pakistan helps students not to worry about their appearance as they do in the United States who do not wear uniform. Students in Pakistan do now wear jewelry or worry about personal appearance the way they worry in the United States."

"In Pakistan, we pay more attention to grammatical and spelling mistakes but in the United States there is no emphasis on grammar and spelling errors."

"Our students in Pakistan are better writers and write with fewer mistakes, particularly the ELLs students. Our students in Pakistan get more difficult work as compared to the context of an ELL classroom."

"Handwriting skills are better in Pakistan. Handwriting teaching is better."

"Daily assembly to open the school day reciting the Holy Quran and prayers, (40 minutes) both religious and moral. It is good because it builds character and requires that the teachers are there to attend the assemblies."

"Children in the U.S. have more resources, but children in Pakistan are more resourceful."

This last question provided information on topics that were clearly important to the participants such as moral development, the teaching of grammar and handwriting, the creativity they see in their students in Pakistan, and the implementation of a dress code that is respectful to the learning institutions where students attend. Their answers also serve as a reminder of how others perceive our educational institutions, our students, and our teachers. Indeed, some of their observations have also been discussed in our own educational settings such as the practice of requiring students to wear uniform, the teaching of handwriting, and the expense of attending higher education in the United State.

It was encouraging to see how the participants identified practices and policies that they considered valuable and beneficial for them as teachers and for the students, while at the same time they were ready to implement many of the new strategies they had learned in their professional development program. 


\section{Discussion and Conclusions}

The questionnaire and the group discussions were designed to elicit general comments of Pakistani secondary teachers about the ways in which the teacher exchange program they attended could advance their teaching skills and practices upon their return to Pakistan. Through their responses, it became apparent that all of the participants considered their experience impactful both professionally and personally. They found that Pakistani schools are similar to the U.S. schools in terms of devoted teachers; standardized examination system; lower salaries for teachers; multilingual classes; and prevalence of private and public setups. They also listed the stark differences in terms of use of technology; activity base learning; institutional practices, culture and norms; curriculum and evaluation system. The respondents commented that the exchange experience assisted them in becoming more reflective of their own teaching practices prompting them to modify their own pedagogical skills.

While commenting on the practices which can be easily replicated in the Pakistani educational context, the respondents agreed that the content, knowledge and skills they learned in terms of lesson planning, classroom management, micro teaching techniques, addressing diversity and meeting individual needs, are highly useful and beneficial. However, they mentioned that the use of sophisticated technological tools in the classroom, addressing the needs of students with special needs, integrating music as a subject, and using libraries as a part of curriculum, would be more challenging as in public schools in Pakistan they lack such advanced resources. The respondents overall agreed that this exchange experience enhanced their understanding of the needs of their own students but that many strategies will need to be modified according to their context.

\section{Recommendations}

The teachers' perceptions and views collected through this study emphasize the benefits of international teacher exchange professional development programs. Such programs have significant implications for public schools in countries such as Pakistan where teachers often do not have access to opportunities for quality professional development. It is recommended that such programs should be continued.

In order to continue confirming the benefits of such programs, follow-up studies should be conducted that explore the impact of these programs once teachers return to their local communities. Studies should 
explore how teachers incorporate new learning into their practices, how they share their knowledge and skills with their colleagues, and which components of these professional development program appear to be the most beneficial to improve general components of education. The crosscultural aspects of such programs can also be studied to explore how these exchange experiences can influence the perception of the cultures and people involved in the exchanges to include not only the international teachers who visit, but also the national teachers and their students. As most studies have concentrated on exploring how these programs benefits international participants, it is reasonable to anticipate that the benefits are not limited to them, but that also the receiving teachers, teacher educators, local students, and community members will also benefit from these exchange programs. 
References

Ahmed, K. (2013). Teacher-centered versus learner-centered teaching style. The Journal of Global Business Management, 9(1), 22-34.

Alexander, R. (2000). Culture and Pedagogy: International Comparisons in Primary Education. Oxford: Blackwell.

Alexander, R. (2001). Border crossings: Towards a comparative pedagogy. Comparative Education, 37(4), 507-523.

Bilash, O., \& Kang, J. (2007). Living well in a changing world: What Korean teachers of English say about a study abroad program in Canada. Journal of Educational Thought, 41(3), 295-309.

Carriedo, R. G., De Nava, J. L., \& Martínez, M. S. (2017). International student teaching: A transformational experience. Journal of International Students, 7(3), 841-855. doi:10.5281/zenodo.570037

Charmaz, K. (2008). Grounded theory as an emergent method. In S. N. Hesse-Biber\& P. Leavy (Eds.), Handbook of emergent methods (pp. 155-170). New York, NY: The Guilford Press.

Cook, R. (2009). The effects of a short-term teacher abroad program on teachers' perceptions of themselves and their responsibilities as global educators. All Graduate Thesis and Dissertations. 375. Retrieved from https://digitalcommons.usu.edu/etd/375.

Corbin, J., \& Strauss, A. L. (2008). Basics of qualitative research: Techniques and procedures for developing grounded theory (3rd ed.). Thousand Oaks, CA: Sage.

Creswell, J. W. (2013). Qualitative inquiry and research design: Choosing among five approaches (3rd ed.). Thousand Oaks, CA: Sage.

Fraenkel, J. R., \& Wallen, N. E. (2006). How to design and evaluate research in education (6 $6^{\text {th }}$ ed.). New York: McGraw-Hill Companies, Inc.

Haider, M. (2014). Do the dare: Give education $4 \%$ of the GDP. News article retrieved from https://www.dawn.com/news/1110128on 18 July 2017. 
Heyl, J. D., \& McCarthy, J. (2003). International education and teacher preparation in the U.S. Paper presented at Global challenges and U.S. higher education: National needs and policy implycations, Duke University, Durham, NC. Retrieved from https://www.dawn.com/news/1110128.

Hussain, A. (March, 2015). Education system of Pakistan: Issues, problems and solutions. Islamabad Policy Research Institute. Retrieved from http://www.ipripak.org/education-system-ofpakistan-issues-problems-and-solutions/

Khan, M. A. (2018). The status of early childhood education in Pakistan: Inside stories. Contemporary Issues in Early Childhood, 19(3), 310-317. doi: 10.1177/1463949118757049

Law, N. (2007). Comparing pedagogical innovations. In M. Bray, B. Adamson, \& M. Mason (Eds.), Comparative education research (pp. 315-337). CERC Studies in Comparative Education. Retrieved from https://linkspringercom.unco.idm.oclc.org/book/10.1007\%2F978-14020-6189-9

Lee, J. (2011). International field experiences-What do student teachers learn? Australian Journal of Teacher Education, 36(10). Retrieved from http://ro.ecu.edu.au/ajte/vol36/iss10/1

Nasrin, A. (2013). An investigation of Pakistani university teacher educators' and student-teachers' perceptions of the role and importance of inquiry-based pedagogy in their professional learning experiences in initial teacher education. $(\mathrm{PhD}$ thesis), University of Glasgow. Retrieved from $\mathrm{http} / / /$ theses.gla.ac.uk/view/creators/Akhter $=3 \mathrm{ANasrin}=3 \mathrm{~A}=3 \mathrm{~A} \cdot \mathrm{htm}$ 1

National Education Policy (2009). Ministry of Education, Government of Pakistan, Revised August 01, 2009. Retrieved from https://www.scribd.com/document/26184511/Pakistan-NationalEducation-Policy-Rev

Patton, M. Q. (2002). Qualitative research \& evaluation methods. Thousand Oaks, CA: Sage. 
Potts, P. (2007). The place of experience in comparative education research. In M. Bray, B. Adamson, \& M. Mason (Eds.), Comparative education research (pp. 63-81). CERC Studies in Comparative Education. Retrieved from

https://link-springer-com.unco.idm.oclc.org/book/10.1007\%2F978-14020-6189-9

Rashid, K., \& Mukhtar, S. (2012). Education in Pakistan: Problems and their solutions. International Journal of Academic Research in Business and Social Sciences, 2(11), Retrieved from

http://hrmars.com/admin/pics/1323.pdf

Rhodes, J. A., \& Milby, T. M. (2016). Advancing teacher education and curriculum development through study abroad programs. Hershey, PA: Information Science Reference.

Rios, F., Montecinos, C., \& van Olphen, M. (2007). Lessons learned from a collaborative self-study in international teacher education: Visiones, preguntas, y desafios. Teacher Education Quarterly, 34(1), 57-74.

Shiveley, J., \& Misco, T. (2015). Long-term impacts of short-term study abroad: Teacher perceptions of pre-service study abroad experiences. Frontiers: The Interdisciplinary Journal of Study Abroad, 26, 107-120. Retrieved from https://frontiersjournal.org/

Smith, K. (2013). Overseas flying faculty teaching as a trigger for transformative professional development. International Journal of Academic Development, 18(2), 127-138. doi: $10.1080 / 1360144 X .2012 .655280$

\section{Citation of this Article:}

Milian, M., \& Yousafzai, S. A. (2019). Advancing public education in Pakistan through a teacher exchange program in the United States. Pakistan Journal of Education, 36(3), 19-38.

DOI: $10.30971 /$ pje.v36i3.766.g208

To link this article: http://dx.doi.org/10.30971/pje.v36i3.766 